\title{
THICK THERMAL BARRIER COATINGS FOR DIESEL ENGINES
}

M.B. Beardsley

Caterpillar, Inc.

Peoria, nlinois
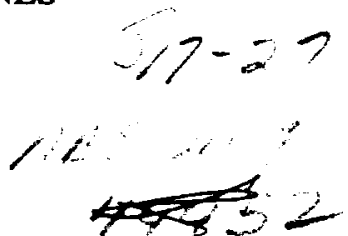

10

Caterpillar's approach to applying Thick Thermal Barrier Coatings (TTBCs) to diesel engine eombustion chambers has been to use advanced modeling techniques to predict engine conditions and combine this information with fundamental property evaluation of TTBC systems to predict engine performance and TTBC stress states. Engine testing has been used to verify the predicted performance of the TTBC systems and provide information on failure mechanisms.

The objective Caterpillar's subcontract with ORNL is to advance the fundamental understanding of thick thermal barrier coating systems. Previous reviews of thermal barrier coating technology concluded that the current level of understanding of coating system behavior is inadequate and the lack of fundamental understanding may impede the application of TTBC's to diesel engines.

Areas of TTBC technology being examined in this program include powder characteristics and chemistry; bond coat composition; coating design, microstructure, and thickness as they affect properties, durability, and reliability; and TTBC "aging" effects (microstructural and property changes) under diesel engine operating conditions. Methods to evaluate the reliability and durability of TTBCs have been developed that attempt to understand the fundamental strength of TTBCs for particular stress states. 